\title{
PREDICTORS OF STRESS \\ AMONG EMERGENCY MEDICAL PERSONNEL DURING THE COVID-19 PANDEMIC
}

\author{
TOMASZ ILCZAK ${ }^{1}$, MAŁGORZATA RAK ${ }^{1,2}$, MICHAŁ ĆWIERTNIA ${ }^{1}$, MONIKA MIKULSKA ${ }^{1}$, \\ WIOLETTA WAKSMAŃSKA ${ }^{3}$, ANNA KRAKOWIAK ${ }^{2}$, RAFAŁ BOBIŃSKI ${ }^{4}$, and MAREK KAWECKI ${ }^{1}$ \\ ${ }^{1}$ University of Bielsko-Biala, Bielsko-Biała, Poland \\ Faculty of Health Sciences, Department of Emergency Medicine \\ ${ }^{2}$ Nofer Institute of Occupational Medicine, Łódź, Poland \\ Toxicology Unit \\ ${ }^{3}$ University of Bielsko-Biala, Bielsko-Biała, Poland \\ Faculty of Health Sciences, Department of Public Health \\ ${ }^{4}$ University of Bielsko-Biala, Bielsko-Biała, Poland \\ Faculty of Health Sciences, Department of Biochemistry and Molecular Biology
}

\begin{abstract}
Objectives: The COVID-19 pandemic has forced emergency services to implement new standards of practice around the world. The dynamic and unpredictable nature of many clinical situations has placed emergency service personnel in direct danger of contracting the disease. This work uses a validated survey developed for the study to assess the predictors of stress that paramedics, nurses and doctors experience in the face of the COVID-19 pandemic. Material and Methods: The study group included 955 medical staff, and the level of significance adopted for statistical analysis was $\mathrm{p}=0.05$. Non-parametric Mann-Whitney and Kruskal-Wallis tests were used to analyze the qualitative variables divided into groups. The selection of tests was carried out based on the distribution of variables, verified using the Shapiro-Wilk test. In order to determine the predictors that caused the feelings of stress, it was necessary to use the linear regression model. Results: During the COVID-19 pandemic, stress among emergency medical personnel has increased considerably due to new factors that did not previously exist. The predictors of stress in the professional environment include the fear of contracting COVID-19, a decrease in the level of safety while conducting emergency medical procedures, and the marginalization of treatment for patients not suffering from COVID-19. Additional socio-demographic factors that increase stress among emergency medical personnel are being female and working in the nursing profession. Appropriate training, the supply of personal protective equipment and opinions on the preparedness of the system to deal with the outbreak of the pandemic did not affect the level of stress among health service personnel. Conclusions: The factors that can be considered to act as predictors of occupational stress include the fear of contracting COVID-19, a decrease in the level of safety and security while conducting emergency medical procedures, and the marginalization of patients not suffering from COVID-19. Int J Occup Med Environ Health. 2021;34(2):139-49
\end{abstract}

Key words:

occupational stress, emergency medical services, COVID-19 pandemic, predictors of stress, medical professionals, emergency procedures

Received: July 14, 2020. Accepted: October 20, 2020.

Corresponding author: Tomasz Ilczak, University of Bielsko-Biala, Faculty of Health Sciences, Department of Emergency Medicine, Willowa 2, 43-309 Bielsko-Biała, Poland (e-mail: tilczak@ath.bielsko.pl). 


\section{INTRODUCTION}

Stress can occur at work in situations when personal and professional demands exceed the ability of an employee to meet such demands, or when that employee is expected to fulfill duties beyond their capabilities [1]. The World Health Organisation (WHO) has shown that stressful situations in professional life are often linked to a lack of the relevant competencies required for carrying out allocated tasks, a low support and motivation from superiors, or a loss of control over situations related to carrying out professional duties [2].

The COVID-19 pandemic has changed patterns of everyday life on all levels. Although the outbreak of the COVID-19 pandemic has changed working environments for all employees, medical professionals must remain in constant readiness to carry out their duties. During the pandemic, it is vital to provide medical services, particularly those relating to the well-being and health of patients. Emergency medical services, which are the first point of contact with patients, constitute the area of the health sector most at risk from COVID-19. This includes emergency medical response teams and hospital emergency wards. With regard to occupational stress affecting the working environment during the COVID-19 pandemic, processes allowing for a full control over professional duties have been disrupted. There is a very long list of threats and changes resulting from the spread of the virus. Due to the epidemiological danger and the lack of a quick test to confirm the infection, personal safety standards during emergency medical procedures involving direct (face-to-face) contact with patients have taken on a new dimension.

The use of protective equipment such as masks, face shields and body suits, which medical staff were not previously equipped with, hampers the manual diagnostic and therapeutic procedures that are vital for the patient's survival. The COVID-19 pandemic has also had a significant effect on the functioning of hospitals and specialist clinics. The transformation of hospitals into centers for infectious diseases has led to situations in which patients whose lives are under direct threat are transported to more distant locations than those that would normally be used. A stricter clinical isolation of patients in hospital emergency wards and the difficulty in conducting complicated medical procedures under the constant risk of contracting the infection have completely changed the working practices of the emergency medical services.

Studies by researchers have clearly shown that the professional group under the highest level of stress are those working in emergency medical services: nurses, doctors and paramedics employed in the ambulance service and in hospital emergency wards [3-5]. The burden borne by emergency medical personnel results in particular from the everyday need to take quick decisions in life-threatening situations, a frequent exposure to the death or suffering of patients, and the inability to provide patients with sufficiently suitable medical care [6-8]. Additional aspects that increase the level of stress among medical personnel are professional factors such as overwork, the necessity to provide professional care at night and on public holidays, poor organization and equipment, the need to take life and death decisions on one's own, and no sense of safety or security [5,9]. Finally, the occurrence and severity of occupational stress is also linked to gender and profession [10].

Increased levels of stress may lead to extremely serious health problems and to the occurrence of many diseases such as cancer or psychiatric disorders. Stress at work has been directly linked to the occurrence of cardiovascular diseases, diabetes, depression and occupational burnout, resulting in a drop in the quality of services [11-12]. During the study period, the average number of diagnosed cases of COVID-19 in Poland was 338/day, and the number of active cases at the end of the study was 8080 [13]. During the COVID-19 pandemic, the existing problems in the health service have not diminished but have only been compounded due to the lower sense of safety and secu- 
rity among medical staff, changes in work practices, and the need to provide medical care under a constant threat of contracting the infection. In this study, the authors examined which professional and socio-demographic factors relating to the work environment have a direct effect on the levels of stress among Polish emergency medical personnel during the COVID-19 pandemic.

\section{MATERIAL AND METHODS}

\section{Methodology}

The study was conducted during the COVID-19 pandemic on March 27-April 20, 2020. The format used was an online questionnaire.

\section{Study group}

When the pandemic broke out in Poland, there were 237 ambulance stations and 1585 emergency medical response teams providing emergency services to patients directly exposed to life-threatening situations. Members of the Polish emergency medical services participated voluntarily in the study, with the study group of $\mathrm{N}=955$ (100\%). According to the data provided by the Central Statistical Office, 12700 employees worked in the emergency system. The study group constitutes $13.2 \%$ of all employees in this sector $[14,15]$. The professional group includes doctors, nurses and paramedics working in ambulance services and hospital emergency departments. The characteristics of the study group are presented in Table 1.

The study was conducted in such a way as to ensure the anonymity of the participants. The criteria for accepting questionnaires included the questionnaires submission by the respondents working in emergency medical services in March 27-April 4, 2020, and the provision of unambiguous answers to all questions. The criteria for rejecting questionnaires were ambiguous responses or a lack of responses to all questions. Three questionnaires that did not contain answers to all the questions were rejected. The remaining study material was accepted for statistical analysis.
Table 1. Demographic characteristics of the medical rescue system employees, March 27-April 20, 2020, Poland

\begin{tabular}{lcc}
\hline \multirow{2}{*}{ Variable } & \multicolumn{2}{c}{$\begin{array}{c}\text { Participants } \\
(\mathrm{N}=955)\end{array}$} \\
\cline { 2 - 3 } Age & $\mathrm{n}$ & $\%$ \\
18-30 years & 342 & 35.80 \\
31-40 years & 419 & 43.90 \\
41-50 years & 145 & 15.20 \\
$>$ 50 years & 49 & 5.10 \\
Gender & & \\
female & 309 & 32.40 \\
male & 646 & 67.60 \\
Profession & & \\
doctor & 116 & 12.10 \\
nurse & 201 & 21.10 \\
paramedic & 638 & 66.80 \\
Place of work & & \\
hospital emergency ward & 390 & 40.50 \\
ambulance team & 565 & 59.50 \\
Education & & \\
technician & 150 & 15.70 \\
Bachelor's degree & 419 & 43.90 \\
Master's degree & 386 & 40.40 \\
\hline
\end{tabular}

\section{Research tools}

The research tool employed was an online questionnaire prepared for conducting the study by the study authors, and validated by the McDonald $\Omega$ test with a satisfactory reliability score of $>0.7$, which confirmed the high quality of the research tool [16]. After validation, the questionnaire contained 24 questions, including 6 questions on demographic characteristics, and 18 questions related to the feelings and opinions of medical staff on the ongoing COVID-19 pandemic. Each question contained a field where the respondents could freely express their opinions on the question topic; however, the completion of this field was not compulsory. The questionnaire was divided into 3 sections. 
The first section related to information about the research tool:

- information on full anonymity, asking respondents not to give any data in their answers which could identify them,

- a clause on the informed consent for participation in the study at the time the questionnaire was completed,

- a declaration by the researchers informing that all data gathered would be used for the purposes of the study, and for the subsequent publication of the results obtained.

- The second section contained questions on demographic characteristics such as age, gender, profession, place of work, work experience and education.

The third section related to information concerning the feelings of medical staff about the COVID-19 pandemic, the preparedness of the Polish emergency medical services for operating in the face of the pandemic, the staff's opinion on the functioning of and compliance with the rules on sanitation during the pandemic, and cooperation between the emergency services and other health care sectors.

As the researchers were aware that medical staff are experiencing a heavy workload during the COVID-19 pandemic, the decision was taken to use the 5-pt Likert scale in order to shorten the time required to complete the questionnaire and to make the use of mobile devices possible. The scale was designed so that the strength of a given phenomenon could be assessed from 1 - no effect to 5 - the strongest effect.

To answer the question on the predictors of stress among personnel of the Polish emergency medical services during the COVID-19 pandemic, the study group was asked the following question: "How would you assess your level of stress while fulfilling your professional duties during the COVID-19 pandemic?" A 5-pt Likert scale was used where 1 - "I am not stressed," and 5 - "I am extremely stressed." In order to obtain answers about the level of stress among emergency medical personnel, 4 research questions were asked. These allowed for assessing the level of stress depending on age, work experience, gender, profession, and the influence of other professional and emotional factors. A research hypothesis was formulated for each question:

- H1: Among emergency medical personnel, age and work experience affects the level of professional stress experienced while carrying out work-related duties during the COVID-19 pandemic.

- H2: Among emergency medical personnel, gender affects the level of professional stress experienced while carrying out work-related duties during the COVID-19 pandemic.

- H3: Among emergency medical personnel, profession affects the level of occupational stress experienced while carrying out work-related duties during the COVID-19 pandemic.

- H4: The feelings of medical staff about the COVID-19 pandemic, an assessment of the preparedness of the Polish emergency medical services for operating in the face of the pandemic, as well as cooperation between the emergency services and other health care sectors affect the level of stress among Polish emergency medical personnel.

The research tool was made available to the respondents via social media and through information on the websites of the institutions involved in conducting the study.

\section{Statistical analysis}

In the statistical analysis, a significance level of $p=0.05$ was adopted. Non-parametric Mann-Whitney and Kruskal-Wallis tests were used to analyze the quantitative variables divided into groups. The selection of tests was carried out based on the distribution of variables, verified using the Shapiro-Wilk test. In order to determine which differences between the groups studied were significant, a pairwise comparison was applied using the post hoc Bonferroni test. In order to determine the predictors that caused the feelings of stress, it was necessary to use 
the linear regression model. The explanatory variable was the level of stress experienced. The remaining questions on working in the emergency medical services during the COVID-19 pandemic were response variables. This enabled testing whether the answers to given particular questions clearly described the feeling of stress. The F-test was then applied to define the total significance of the regression parameters. The $\beta$ coefficient was then used to test the strength of the response variables and to link them to the explanatory variable. The calculations were carried out in the R statistical environment v. 3.6.0, the PSPP program and MS Office 2019.

\section{RESULTS}

According to the information provided by the Central Statistical Office, 12700 employees work in the Polish rescue system. The study group consisted of 955 people working in the emergency medical system in Poland, who voluntarily took part in the study.

In order to conduct the statistical analysis and to compare the independent variable of the experienced level of stress depending on age and work experience, it was necessary to use a non-parametric Kruskal-Wallis test. There were no statistically significant differences in the perception of occupational stress depending on age $(p=0.724)$ and work experience $(\mathrm{p}=0.680)$. The results obtained are presented in Table 2.

In order to check how gender influences the perception of stress in the emergency medical personnel during the COVID-19 pandemic, with gender distribution was performed for each of the medical professions. Its results are presented in Table 3.

The division by gender in the study group was as follows: 309 women (32.4\%), and 646 men (67.6\%). In order to prove the assumed hypothesis, the Mann-Whitney U independent sample test was applied. The results of the calculations for the 2 genders were as follows: among men, the arithmetic mean $(\mathrm{M})$ of the answers was 3.56 , while among women, it was 4.05. The median (Me) of answers in both groups was 4.0 with a standard deviation (SD) of 1.12 among men, and 1.00 among women. The statistical test value for the parameter analyzed was $U=74833.50$. The results obtained illustrate that women working in the emergency medical services define their level of stress as significantly higher than men in the same profession. The level of statistical significance was $p<0.001$. Based on these results, the hypothesis that gender affects the level of stress experienced among emergency medical personnel can be adopted.

The distribution of professions in the study group was as follows: 201 nurses $(21.1 \%)$, doctors $116(12.1 \%)$, and

Table 2. Influence of age and work experience on the perception of stress among employees of the emergency medical system, March 27-April 20, 2020, Poland

\begin{tabular}{lcccccccc}
\hline \multicolumn{1}{c}{ Variable } & $\chi^{2}$ & $\mathrm{df}$ & $\mathrm{p}$ & $\mathrm{M}$ & $\mathrm{SD}$ & $\mathrm{Min}$. & $\mathrm{Max}$ & $\mathrm{Me}$ \\
\hline Age & 0.65 & 2 & 0.724 & & & & & \\
18-30 years & & & & 3.72 & 1.07 & 1.00 & 5.00 & 4.00 \\
31-40 years & & & & 3.76 & 1.12 & 1.00 & 5.00 & 4.00 \\
$\quad$ 40 years & 0.77 & 2 & 0.680 & & & & & \\
Work experience & & & & 3.66 & 1.08 & 1.00 & 5.00 & 4.00 \\
$\quad$ 5 years & & & & 3.78 & 1.11 & 1.00 & 5.00 & 4.00 \\
6-15 years & & & & 3.69 & 1.14 & 1.00 & 5.00 & 4.00 \\
\hline 15 years & & & & & & & & \\
\hline
\end{tabular}

$\mathrm{Chi}^{2}$ - test statistic; df - degrees of freedom; min. - minimum result; max - maximum result. 
Table 3. Gender distribution for each of the medical professions of the study group, March 27-April 20, 2020, Poland

\begin{tabular}{lcccc}
\hline & \multicolumn{4}{c}{$\begin{array}{c}\text { Participants } \\
(\mathrm{N}=955)\end{array}$} \\
\cline { 2 - 5 } Profession & $\begin{array}{c}\text { female } \\
(\mathrm{N}=309,\end{array}$ & \multicolumn{2}{c}{$\begin{array}{c}\text { male } \\
\mathrm{N}=646, \\
\end{array}$} & \multicolumn{2}{c}{$32.4 \%)$} & \multicolumn{2}{c}{$67.6 \%)$} \\
\hline Nurse & $\mathrm{n}$ & $\%$ & $\mathrm{n}$ & $\%$ \\
Paramedic & 119 & 59.30 & 82 & 40.70 \\
Doctor & 126 & 19.80 & 512 & 80.20 \\
\hline
\end{tabular}

638 paramedics $(66.8 \%)$. In order to conduct the statistical analysis and to compare the independent variable of the experienced level of stress for each profession, it was necessary to use a non-parametric Kruskal-Wallis test. The results obtained are presented in Table 4.

In the range of the variable, the level of stress in the groups divided by profession differs to a statistically significant degree $(p=0.002)$. To define more precisely the groups between which statistically significant differences were found to occur, it was necessary to compare the professions in pairs and to conduct a post hoc Bonferroni test. A comparison of the level of stress between professions revealed that, relative to paramedics, nurses experienced a statistically higher level of stress at work during the COVID-19 pandemic ( $p=0.009)$. However, no statistically significant differences were found between paramedics and doctors $(\mathrm{p}=1.00)$, or between nurses and doctors $(\mathrm{p}=0.432)$. On the basis of these results, the hypothesis can be drawn that the type of the medical profession performed affects the stress experienced during the COVID-19 pandemic.

To analyze the assumed hypothesis, a linear regression model was applied. The explanatory variable was the level of stress, and the response variables were the questions addressed to medical personnel during the study. The linear regression model was applied in order to answer the question whether the statistical model satisfactorily explains the variation in the level of stress experienced in relation to the answers to other questions. The F-test was applied and a result of $\mathrm{F}=27.18$ was obtained, with a statistical significance of $p<0.001$. The result obtained allowed for the correlation of the effect of individual study components on the level of stress experienced among emergency medical personnel during the COVID-19 pandemic. The statistical significance of the correlation of individual study questions in relation to the experienced level of stress among emergency medical personnel is presented in Table 5.

A detailed analysis showed a statistically significant influence of the questions assessing the feeling of safety and security among employees when carrying out medical intervention on a patient with suspected COVID-19 ( $\mathrm{p}<0.001)$, concerns about becoming infected with COVID-19 ( $p<0.001)$, and the marginalization by medical services of patients not suffering from COVID-19 $(\mathrm{p}<0.014)$. In the case of the feeling of safety and se-

Table 4. Differences in the levels of stress experienced in the emergency medical services according to profession, March 27-April 20, 2020, Poland

\begin{tabular}{|c|c|c|c|c|c|}
\hline Profession* & $\mathrm{M}$ & SD & Min. & $\operatorname{Max}$ & $\mathrm{Me}$ \\
\hline Nurse & 3.92 & 1.14 & 1.00 & 5.00 & 4.00 \\
\hline Paramedic & 3.73 & 1.11 & 1.00 & 5.00 & 4.00 \\
\hline Doctor & 3.66 & 1.09 & 1.00 & 5.00 & 4.00 \\
\hline
\end{tabular}

${ }^{*} \mathrm{Chi}^{2}=12.12, \mathrm{df}=2, \mathrm{p}=0.002$.

Abbreviations as in Table 2. 
Table 5. Correlation of individual research factors in relation to the experienced level of stress among emergency medical personnel, March 27-April 20, 2020, Poland

\begin{tabular}{|c|c|c|c|c|c|}
\hline Questions & SE & $\beta$ & df & $\mathrm{t}$ & $\mathrm{p}$ \\
\hline "Were you trained in procedures regarding protecting yourself from the infection?" & 0.031 & 0.042 & 937 & 1.358 & 0.175 \\
\hline $\begin{array}{l}\text { "How would you assess the preparedness of the emergency services with regard } \\
\text { to providing protection in emergency medical interventions in the face } \\
\text { of the global pandemic?" }\end{array}$ & 0.033 & -0.025 & 937 & -0.766 & 0.444 \\
\hline $\begin{array}{l}\text { "Do you feel safe carrying out medical interventions on patients with suspected } \\
\text { COVID-19?" }\end{array}$ & 0.034 & -0.144 & 937 & -4.269 & $<0.001$ \\
\hline $\begin{array}{l}\text { "In your workplace, are you provided with sufficient personal protective } \\
\text { equipment?" }\end{array}$ & 0.027 & 0.020 & 937 & 0.727 & 0.467 \\
\hline $\begin{array}{l}\text { "How would you assess cooperation between the emergency services, infectious } \\
\text { disease prevention centers and other medical services?" }\end{array}$ & 0.029 & 0.050 & 937 & 1.725 & 0.085 \\
\hline $\begin{array}{l}\text { "Have medical isolation systems for patients with COVID-19 been appropriately } \\
\text { adapted to the conditions of the pandemic?" }\end{array}$ & 0.030 & 0.056 & 937 & 1.847 & 0.065 \\
\hline $\begin{array}{l}\text { "In your opinion, how much are you at risk from serious threat to your health } \\
\text { and well-being in the case of the SARS-CoV-2 infection?" }\end{array}$ & 0.031 & 0.044 & 937 & 1.431 & 0.153 \\
\hline $\begin{array}{l}\text { "In your opinion, were the emergency services sufficiently prepared } \\
\text { for the outbreak of a global pandemic?" }\end{array}$ & 0.030 & -0.040 & 937 & -1.340 & 0.181 \\
\hline $\begin{array}{l}\text { "Do you think that patients in a critical condition not suffering from COVID-19 } \\
\text { are more marginalized by the medical services than before the epidemic?" }\end{array}$ & 0.027 & -0.067 & 937 & -2.456 & 0.014 \\
\hline "Are you afraid that you will become infected with COVID-19?" & 0.032 & 0.474 & 937 & 14.661 & $<0.001$ \\
\hline
\end{tabular}

df - degrees of freedom; $\beta-\beta$ coefficient; $t$ - test statistic.

curity while working with a patient suspected of being infected with the virus, the $\beta$ coefficient value was -0.144 . This means that when the feeling of safety and security increases by $1 \mathrm{pt}$ on the Likert scale, there is a drop in stress by 0.14 units. The $\beta$ coefficient value for the marginalization of patients was -0.067 , which means that the more often patients not suffering from COVID-19 are marginalized by medical services, the greater the feeling of stress among emergency medical personnel. The $\beta$ coefficient value for concerns about becoming infected was 0.474 , which means that the greater the worry among the respondents about becoming ill, the higher their levels of stress. A change in the strength of this fear by $1 \mathrm{pt}$ on the Likert scale caused an increase in the feeling of stress by 0.474 units. Therefore, the feeling of safety and security, the marginalization of patients and the fear of falling ill are the variables which can be considered statistically significant predictors of stress, and in this respect the hypothesis can be accepted.

\section{DISCUSSION}

The COVID-19 pandemic affects the field of work in many respects, and in particular the medical professions. One aspect of professional life that, according to research, is felt particularly severely is occupational stress, as illustrated by Polish emergency medical personnel. This research is pioneering in that it was conducted during an ongoing pandemic, and cannot be verified against any earlier research. Based on the literature available and the authors' own experiences relating to work during the COVID-19 pandemic, they attempted to find explanations for the results obtained during the study. 
During the analysis of the public emergency medical services, it must be noted that both men and women work in all the medical professions, and in the last 10 years in Poland there has been an increase in the number of women working in ambulances and hospital emergency wards. Publications on the differences in occupational stress experienced by men and women are divergent and cannot be conclusively interpreted. In their research, Vermeulen et al. [17] pointed to the fact that physically active work involving an intense effort increased the level of stress in both women and men. In an analysis of the Spanish health sector employees, Povedano-Jimenez et al. [18] presented a model of demographic characteristics that had an influence on the experienced level of occupational stress. They showed that among medical personnel, those who displayed the greatest resistance to difficult and stressful situations were men aged $>31$ years with $>10$ years of work experience. Wu et al. [19] demonstrated in their study that men were more resistant to occupational stress than women, while in Ireland, it was reported that female doctors significantly more often experienced stress in their work than men [20].

Relating these findings to the present research, it can be confirmed that, within the study group, women experienced a higher degree of stress than men. This confirms the lower resistance to stress among women as described in the literature. The ongoing COVID-19 pandemic has brought additional occupational factors that were not previously described in the literature. The analysis of the material collected in terms of other characteristics dependent on gender, indicated by the respondents as affecting their level of stress, showed that women were decidedly more concerned about becoming infected with SARS-CoV-2 than men, and considered sanitation procedures as not sufficiently adhered to in society at large.

Johnson et al. [4] analyzed 25 professions and demonstrated that paramedics were most at risk of suffering from workrelated stress. The authors explained this by the difficulties faced with decision-making, the stress related to treating patients in life-threatening situations, and the necessity to quickly take key decisions affecting the life and well-being of patients. In contrast, the present research revealed that the respondents with the highest levels of stress were nurses, who demonstrated a much higher degree of stress than paramedics. Looking at the results in terms of the professional duties carried out by doctors, paramedics and nurses, there are some clear differences. The work of paramedics usually involves immediate patient care and transport of patients to hospital, and the tests and procedures carried out by doctors require much less time than the care provided by nurses. The longer periods which nurses spend in direct contact with patients suffering from COVID-19 may additionally compound the level of stress due to a greater possibility of contracting the infection. It should be noted that during the pandemic, prolonged exposure to patients with COVID-19 increases the risk of becoming infected [21]. Another aspect described in the literature that increases the level of stress among nurses is being overburdened with professional duties. Research has shown that excessive work-related duties can lead to an increase in stress and even to occupational burnout [22]. In their study, Ayman et al. [23] showed that stress increased among nurses due to a lack of nursing staff, while British researchers proved that an increase in the number of staff caring for patients lowered the levels of stress among medical professionals [24]. The current situation of the Polish emergency services confirms the findings made by these researchers. The nursing profession is one of the most overworked medical professions in Poland. The necessity to work extra shifts, in addition to working at night, as well as the excessive number of work-related duties all affect the levels of stress among nursing staff. Currently, the Polish health service is struggling with a serious problem of insufficient nursing staff, and training centers are unable to provide enough personnel to match the needs of the health system. Personnel shortages have worsened during the pandemic, with the official website of the nursing union reporting 
on May 7, 2020 that 1637 nurses were either in quarantine or had contracted COVID-19 [25].

Aspects that were considered during the planning of the study to be the key predictors of stress, such as appropriate training, the supply of personal protective equipment or opinions on the preparedness of the health system for the outbreak of the pandemic, did not have a statistically significant effect on the levels of stress among health care staff. The key predictors of stress in the study group related to their feelings connected with providing emergency medical care during the pandemic. The key predictors indicated by the respondents were the fear of contracting the disease, a decrease in the feeling of safety and security while carrying out work-related duties, and the marginalization of critically ill patients not suffering from COVID-19. The fear of falling ill, and a low feeling of safety and security have been indicated many times by researchers as factors that generate occupational stress [26]. This is also confirmed by this study.

The appearance of a new, dangerous and unknown disease that emergency medical personnel are faced with in their work increases stress during emergency medical procedures, and additionally decreases their feeling of safety and security. The ease with which the disease can be transmitted seriously affects the possibility of protecting oneself fully from the infection, and thus increases the fear of contracting the infection among medical personnel. The marginalization of patients not suffering from COVID-19 is a new phenomenon not previously seen anywhere in the world, and it is, therefore, impossible to compare it with the findings of similar studies.

International researchers have demonstrated that the provision of high quality health care service to patients has a direct effect on work satisfaction [27]. Bovier et al. [28] and Rizivi et al. [29] proved in their research that the psychological well-being of doctors depended on the quality of care provided to patients. The wider the range of treatment options available, the higher the level of work satisfaction. In spite of the competencies of medical staff, the COVID-19 pandemic has led to a drop in the quality of care provided. A frequent lack of access to specialist treatment units and the closure of hospital wards due to quarantine has led to a decrease in the quality of care for patients requiring urgent medical assistance.

In this study, the authors also analyzed remarks submitted by the respondents on the marginalization of patients not suffering from COVID-19. It was noted several times in the comments made by the respondents that during the COVID-19 pandemic patients had severely limited access to specialist care. The patients requiring immediate assistance are transported to hospitals considerably further away from their place of residence due to frequent closures of hospital wards. The time required to issue a final diagnosis and to start appropriate treatment is prolonged due to the necessity of ensuring that the patient does not become infected with the virus. Situations have also been reported in which patients requiring hospitalization refuse to be transported to hospital in fear of being infected by hospital staff or other patients.

These factors all negatively impact on the proper completion of professional duties by Polish emergency medical personnel. A comparison of the results of this study with the opinions of other researchers confirms that a drop in professional well-being and the inability to properly carry out professional duties causes an increase in stress among Polish emergency medical personnel [30].

\section{CONCLUSIONS}

The factors that can be considered to be the predictors of occupational stress include the fear of contracting COVID-19, a decrease in the level of safety and security while conducting emergency medical procedures, and the marginalization of patients not suffering from COVID-19. Being female and working in the nursing profession are additional socio-demographic factors that increase the levels of stress among emergency medical personnel. Appropriate training, the supply of personal protective equipment and opinions on the preparedness of 
the health system for the outbreak of the pandemic did not affect the levels of stress among health sector employees.

\section{Data transparency}

Data reported in this manuscript have not been published before and have been collected as part of a larger dataset, under a European survey project on the opinions of rescue system employees. In this study, variables such as gender, occupation, and the level of stress experienced were used. The level of stress was referred to variables such as the preparation of a rescue system, a sense of security, the availability of self-protection resources, a sense of fear of the infection, and a marginal treatment of patients without COVID-19. The variables and relationships examined in the present article have not been examined in any previous or current articles or, to the best of the authors' knowledge, in any papers that will be under review soon. All data collected during the study are available from the authors and can be made available at the request of interested researchers.

\section{REFERENCES}

1. Cohen S, Janicki-Deverts D, Miller GE. Psychological stress and disease. JAMA. 2007;298(14):1685-7, https://doi.org/10. 1001/jama.298.14.1685.

2. World Health Organization [Internet]. Geneva: The Organization; 2020 [cited 2020 May 7]. Stress at the workplace. Available from: https://www.who.int/occupational_health/ topics/stressatwp/en/.

3. Halpern J, Maunder RG, Schwartz B, Gurevich M. Downtime After Critical Incidents in Emergency Medical Technicians/Paramedics. Biomed Res Int. 2014;2014:483140, https://doi.org/10.1155/2014/483140.

4. Johnson S, Cooper C, Cartwright S, Donald I, Taylor PJ. The Experience of Work-Related Stress across Occupations. J Manage Psychol. 2005;20(2):178-87, https://doi. org/10.1108/02683940510579803.

5. Alexander DA, Klein S. Ambulance personnel and critical incidents: impact of accident and emergency work on mental health and emotional well-being. Br J Psychiatry. 2001;178(1):76-81, https://doi.org/10.1192/bjp.178.1.76.

6. McFarlane AC, Bryant RA. Post-traumatic stress disorder in occupational settings: anticipating and managing the risk. Occup Med. 2007;57(6):404-10, https://doi.org/10.1093/occmed/kqm070.

7. Mitchell JT. When disaster strikes: the critical incident stress debriefing process. JEMS. 1983;8(1):36-9, https://doi. org/10.1155/2014/483140.

8. Halpern J, Gurevich M, Schwartz B, Brazeau P. What makes an incident critical for ambulance workers? Emotional outcomes and implications for intervention. Work Stress. 2009;23(2):173-89, https://doi.org/10.1080/026783709030 57317.

9. Cheung T, Yip PS. Lifestyle and Depression among Hong Kong Nurses. Int J Environ Res Public Health. 2005;12(9): 11072-100, https://doi.org/10.3390/ijerph13010135.

10. Padkapayeva K, Gilbert-Oimet M, Bielecky A, Ibrahim S, Mustard C, Brisson C, et al. Gender/Sex Differences in the Relationship between Psychosocial Work Exposures and Work and Life Stress. Ann Work Expo Health. 2018;62(4):416-25, https://doi.org/10.1093/annweh/wxy014.

11. Siegrist J, Li J. Associations of Extrinsic and Intrinsic Components of Work Stress with Health: A Systematic Review of Evidence on the Effort-Reward Imbalance Model. Int J Environ Res Public Health. 2016;13(4):432, https://doi. org/10.3390/ijerph13040432.

12. De Araujo TM, Siegrist J, Moreno AB, de Jesus Mendes da Fonseca M, Barreto SM, Chor D, et al. Effort-Reward Imbalance, Over-Commitment and Depressive Episodes at Work: Evidence from the ELSA-Brasil Cohort Study. Int J Environ Res Public Health. 2019;16(17):3025, https:/doi. org/10.3390/ijerph16173025.

13. Worldometers [Internet]. Total Coronavirus Cases in Poland [cited 2020 Oct 10]. Available from: https://www.worldometers.info/coronavirus/country/poland.

14. Website of the Republik of Poland [Internet]. Warsaw: Ministry of Health; Emergency Wards. [cited 2020 May 7]. 
Szpitalne oddziały ratunkowe. Available from: https://www. gov.pl/web/zdrowie/szpitalne-oddzialy-ratunkowe. Polish.

15. Statistics Poland [Internet]. Warsaw: Statistics Poland; 19952020 [cited 2020 Oct 10]. First Aid and emergency medical services in 2019. Available from: https://stat.gov.pl/en/topics/ health/health/first-aid-and-emergency-medical-services-in2019,7,4.html.

16. Ventura-León JL, Caycho-Rodriguez T. El coeficiente Omega: un método alternativo para la estimación de la confiabilidad. Revista Latinoamericana de Ciencias Sociales, Niñez y Juventud [Internet]. Manizales: Centro de Estudios Avanzados en Niñez y Juventud; 2017 [cited 2020 May 7]. Available from: https://www.redalyc.org/articulo.oa?id=77349627039. Spanish.

17. Vermeulen M, Mustard C. Gender differences in job strain, social support at work, and psychological distress. J Occup Health Psychol. 2000;5(4):428-40, https://doi.org/10.1037/ /1076-8998.5.4.428.

18. Povedano-Jimenez M, Granados-Gamez G, Garcia-Caro MP. Work environment factors in coping with patient death among Spanish nurses: a cross-sectional survey. Rev Lat Am Enfermagem. 2020;28:e3234, https://doi.org/10.1590/1518-83 45.3279.3234.

19. Wu TW, Oliffe JL, Bungay V, Johnson JL. Male ICU nurses' experiences of taking care of dying patients and their families: a gender analysis. Am J Mens Health. 2015;9(1):44-52, https://doi.org/10.1177/1557988314528236.

20. O'Dowd E, O'Connor P, Lydon S, Mongan O, Connolly F, Diskin C, et al. Stress, coping, and psychological resilience among physicians. BMC Health Serv Res. 2018;18(1):730, https://doi.org/10.1186/s12913-018-3541-8.

21. Guan W-J, Ni Z-Y, Hu Y, Liang W-H, Ou C-Q, He J-X, et al. Clinical Characteristics of Coronavirus Disease 2019 in China. N Engl J Med. 2020;382:1708-20, https://doi. org/10.1056/NEJMoa2002032.
22. Wu S, Zhu W, Wang Z, Wang M, Lan Y. Relationship between burnout and occupational stress among nurses in China. J Adv Nurs. 2007;59(3):233-9, https://doi.org/10.1111/ j.1365-2648.2007.04301.x.

23. Ayman AN, Fouad A, Murad AY, Nabeel AY, Nazih AT. Nurses' perceived job related stress and job satisfaction in Amman Private Hospitals. [Internet] CiteSeer 2005 [cited 2020 May 10]. Available from: http://citeseerx.ist.psu.edu/viewdoc/ download?doi=10.1.1.604.1791\&rep=rep1\&type $=$ pdf.

24. Finlayson B, Dixon J, Meadows S, Blair G. Mind the gap: the extent of the NHS nursing shortage. BMJ. 2002;325(7363): 538-41, https://doi.org/10.1136/bmj.325.7363.538.

25. National Society of Nurses and Midwives [Internet]. Warsaw: The Society; 2020 [cited 2020 May 7]. Available from: https://twitter.com/ozzpip_.

26. Cheung T, Yip PS. Lifestyle and Depression among Hong Kong Nurses. Int J Environ Res Public Health. 2016;13(1): 135, https://doi.org/10.3390/ijerph13010135.

27. Scheepers RA, Boerebach BC, Arah OA, Heineman MJ, Lombarts KM. A Systematic Review of the Impact of Physicians' Occupational Well-Being on the Quality of Patient Care. Int J Behav Med. 2015;22(6):683-98, https://doi.org/ 10.1007/s12529-015-9473-3.

28. Bovier PA, Perneger TV. Predictors of work satisfaction among physicians. Eur J Public Health. 2003;13(4):299-305, https://doi.org/10.1093/eurpub/13.4.299.

29. Rizvi R, Raymer L, Kunik M, Fisher J. Facets of Career Satisfaction for Women Physicians in the United States: A Systematic Review. Women Health. 2012;52(4):402-21, https:// doi.org/10.1080/03630242.2012.674092.

30. Yahaya A, Yahaya N, Arshad K, Ismail J, Jaalam S, Zakariya Z. Occupational Stress and its Effects towards the Organization Management. J Soc Sci. 2009;5(4):390-7, https:// doi.org/10.3844/jssp.2009.390.397.

This work is available in Open Access model and licensed under a Creative Commons Attribution-NonCommercial 3.0 Poland License - http://creativecommons.org/ licenses/by-nc/3.0/pl/deed.en. 